\title{
Modelling electrical interconnections for Rhodes island power system
}

\author{
Eleni Zafeiratou \\ University College London, \\ Energy Institute \\ London, United Kingdom \\ e.zafeiratou@ucl.ac.uk
}

\author{
Catalina Spataru \\ University College London, \\ Energy Institute \\ London, United Kingdom \\ c.spataru@ucl.ac.uk
}

\begin{abstract}
Remote island power systems often fail to enjoy the right to secure, clean energy supply. This paper presents a short-term analysis for the electrical system of Rhodes-Halki in South Aegean, with the use of a mixed-integer dispatch module in PLEXOS $®$ Simulation Software. While examining the impact of submarine grid extensions, the results show that following the interconnection of Rhodes' power system, rapid renewable energy deployment is recorded, allowing for electricity exports equal to $220 \mathrm{MWh}$ by 2040. Power generation costs decline by $58.9 \%$ for the week recording MAX demand and $54.8 \%$ for the week recording MIN demand, compared to the BAU autonomous scenario. The scenario imposing generation restrictions according to directives 2010/75/EU and 2015/2193/EU shows high levels of unserved hourly energy equal to $70 \%-85 \%$.
\end{abstract}

Keywords - island, autonomous power system, interconnections, renewable energy, electricity modelling, mixed integer programming, PLEXOS

\section{NOMENCLATURE}

Indices

g generator

$\mathrm{t}$ dispatch period

y $\quad$ year $\mathrm{y}=1$.. Y

Constants

$\mathrm{BC}_{\mathrm{g}} \quad$ overnight build cost of generator $\mathrm{g}$ or transmission line d discount rate

FO\&M fixed operations and maintenance cost of generator $\mathrm{g}$

FOR Forced Outage Rate

HR Heat Rate

$\mathrm{Pmax}_{\mathrm{g}} \quad$ maximum generating capacity of each unit of generator g

VO\&M variable operations \& maintenance costs

VOLL value of lost load (energy shortage price)

Variables

DF discount factor $\left[D_{y y}=1 /(1+d) y\right]$

FORh Forced Outage Hours

GBg,y number of generating units build in year $y$ for generator $g$

$\mathrm{GL}_{\mathrm{g}} \quad$ dispatch level of generating unit $\mathrm{g}$ in period $\mathrm{t}$

$\mathrm{L}_{\mathrm{t}} \quad$ duration of dispatch period $\mathrm{t}$

MaxGB $_{g . y}$ maximum number of units of generator $\mathrm{g}$ allowed to be built by the end of year $y$

Oh operating hours

Units $_{\mathrm{g}} \quad$ number of installed generating units of generator $\mathrm{g}$

$\mathrm{USE}_{\mathrm{t}} \quad$ unserved energy of dispatch period $\mathrm{t}$

\section{INTRODUCTION}

\section{A. Motivation and Background}

Interconnection of remote islands' power grids could enhance system reliability and allow higher levels of renewable energy integration. In the post Paris Agreement era, European islands have been in the spotlight of policy makers with the establishment of the Clean Energy for European Islands Initiative. This project aims to enhance public and political awareness and tackle key challenges on remote islands related to: high power generation costs, renewable energy sources (RES), carbon emissions, energy security and oil import dependence [1].

This paper focuses on the analysis of a representative Greek insular power system, Rhodes-Halki and its potential to decarbonise its electrical system by 2040 . Rhodes island $\left(1401 \mathrm{~km}^{2}\right)$ is interconnected with the smaller island of Halki $\left(37 \mathrm{~km}^{2}\right)$, both part of the Dodecanese islands' complex in the South Aegean Region (Fig. 1). TABLE I summarises key techno-economic statistics for Rhodes electrical system. It is evident that the average variable production costs record values three times higher than the average electricity production cost in the National Grid System. The annual costs are reflected in the public service obligation account, equal to $13.4 \%$ of the total costs.

The Greek islands including Rhodes are blessed with wind speeds ranging between 8 and $11 \mathrm{~m} / \mathrm{s}$ and average solar irradiation exceeding $1900 \mathrm{kWh} / \mathrm{m}^{2}$. Nonetheless, the wind and solar energy potential has been underutilised to secure the autonomous power grid reliability. TABLE II. summarises the current status of Rhodes in terms of the electricity capacity mix. Renewable energy generation deriving from wind and solar photovoltaic installations is limited to $17 \%$ of the island's electricity mix. The remaining of the electricity demand is supplied through oilfired internal combustion engines (ICE), steam engines (ST) and gas turbines (GT) using either mazut or diesel fuel.

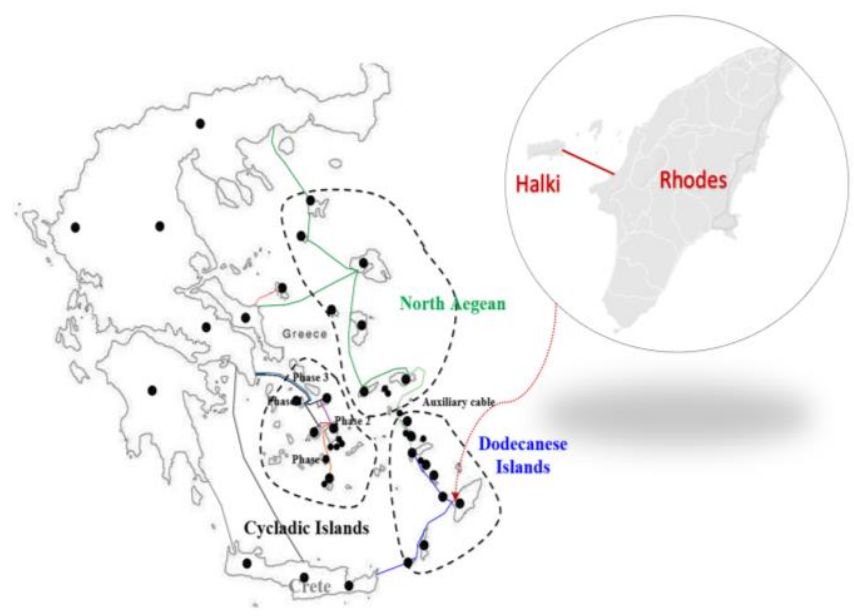

Fig. 1. Map of the Greek islands interconnection plans

TABLE I. DEMAND AND Costs Statistics (2016) [2], [3]

\begin{tabular}{|l|l|l|l|l|}
\hline $\begin{array}{l}\text { Demand } \\
\text { (MWh) }\end{array}$ & $\begin{array}{l}\text { Peak } \\
\text { Demand } \\
\text { (MW) }\end{array}$ & $\begin{array}{l}\text { Average } \\
\text { Variable Pr. } \\
\text { Cost } \\
(\mathbf{G} / \text { MWh })\end{array}$ & $\begin{array}{l}\text { Average Full } \\
\text { Pr. Cost } \\
\text { (€/MWh) }\end{array}$ & $\begin{array}{l}\text { Public } \\
\text { Service } \\
\text { Obligation } \\
\text { (Mil } \boldsymbol{\epsilon})\end{array}$ \\
\hline $816,597.8$ & 200 & 153.6 & 198.6 & 64.8 \\
\hline
\end{tabular}


TABLE II. INSTALLED CAPACITY PER UNIT TYPE IN 2017 (MW) [4]

\begin{tabular}{|l|r|r|r|r|r|r|}
\hline $\begin{array}{l}\text { Autonomous } \\
\text { System }\end{array}$ & \multicolumn{3}{|c|}{$\begin{array}{c}\text { Thermal Power } \\
\text { Generators } \\
\text { (MW) }\end{array}$} & \multicolumn{2}{c|}{$\begin{array}{c}\text { Renewables } \\
\text { (MW) }\end{array}$} & $\begin{array}{c}\text { Total } \\
\text { (MW) }\end{array}$ \\
\cline { 2 - 6 } & ST & ICE & GT & PV & Wind & \\
\hline Rhodes & 29 & 100 & 86.5 & 48.55 & 18.16 & 282.21 \\
\hline
\end{tabular}

\section{B. Relevant Literature}

The autonomous operation of small Greek islands with high RES penetration using hourly dispatch resolution has been extensively investigated by several research papers, primarily in terms of sizing wind and hydro-pumped storage systems [5], [6], [7]. The results proved that the local wind potential and the size of the reservoir plays an important role in achieving energy autonomy on islands, while bringing down costs to $25-30 \%$ compared to the current electricity prices on islands systems.

On the other hand, the interconnection of the islands using a unit commitment, full resolution model while investigating cost savings and operational conditions for the Greek islands has been marginally covered in the literature. In [8] the interconnection of Crete and Thera islands was examined with the use of PowerWorld® Software for simulating the transmission system. The dispatch profiles were analysed showing that wind power curtailment on Crete can be reduced by $74 \%$, proving that the most expensive units located in Thera will eventually reduce their operation. A similar approach to the one investigated herein is presented by [9] confirming that marginal prices are reduced on the island in parallel with RES integration, following the interconnection of Crete with the mainland. The interconnection is judged profitable only if rapid RES development is recorded.

\section{Contribution and Organisation}

This paper presents for the first time, interconnection scenarios for a Greek island with the use of a sophisticated commercial tool, while coupling long-term energy planning with short term scheduling in high spatio-temporal resolution. In parallel, the impact of power generation restrictions as imposed by the Directives 2010/75/EU and 2015/2193/EU ${ }^{1}$ in Rhodes power system is investigated. Three scenarios were incorporated in the analysis. Two associated with the autonomous context: A) a Business As Usual (BAU) Scenario assuming the continuation of the autonomous operation on the islands, including energy storage (hydropower and solar thermal); B) an Autonomous Scenario assuming the application of the aforementioned directives as of 2030 without the necessary market and legal framework to allow rapid acceleration of RES coupled with energy storage for covering baseload demand and C) the Interconnection Scenario assuming the timely construction of all the proposed interconnections as well as rapid acceleration of renewable energy sources.

${ }^{1}$ As of 2020, oil-fired steam and gas turbines are restricted to 1,500 and 500 hours of operation per year from 2020. From 2030, this number decreases to 500 hours horizontally, assumed in the present analysis to include diesel power engines as well.

\section{ELECTRICITY MODELLING METHODOLOGY}

The present analysis was performed by PLEXOS integrated energy model. In the context of this study, PLEXOS is used for electricity market scheduling and dispatching. It is a commercially available proprietary tool offered at no cost for academic, non-commercial research. The formulated model was solved by EELPS solver and rounded relaxation.

\section{A. Scheduling and Dispatch Approach}

PLEXOS incorporates three interrelated chronological simulation modules: the Long Term (LT) plan, ran between 2020 and 2040 with annual time steps, the Medium-Term (MT) Schedule ran for a week with a daily time step and the Short-Term (ST) Schedule developed to cover different chronological granularities. The results presented in the current analysis is an outcome of the ST schedule, using transmission and generation capacity expansion outcomes deriving from the LT plan. The LT plan seeks to minimize the total net present value of the system's costs while finding the optimum generation mix as described in (1) under a number of certain constraints (2)-(4) [10]. MT facilitated the optimization of medium to long-term decisions, before progressing to the ST for modelling the system in full chronological resolution. The ST simulations were performed for two weekly horizons within a year using an hourly time step. The ST module obtains the leastcost dispatch of each power plant in the system to meet a given demand profile. PASA module was activated for capturing maintenance events and loss of load indicators.

$$
\begin{aligned}
\sum_{y, g} D F_{y} *\left(B C_{g}\right. & \left.* G B_{g, y}\right) \\
& +\sum_{y} D F_{y} * \text { FO\&MCost } * \text { Pmax }_{g} *\left(\text { Units }_{g}\right. \\
& \left.+\sum_{y \leq Y} G B \text { Units }_{g, y}\right) \\
& +\sum_{t} D F_{y} * G L_{g, t} *(H R * \text { Fuel Price }+ \text { VO\&M })+\sum_{t} D F_{t \in y} * L_{t} \\
& *\left(\text { VOLL } * U S E_{t}\right)
\end{aligned}
$$

Subject to the following constraints:

Energy Balance: $\sum_{(\mathrm{g})} \mathrm{GL}_{(\mathrm{g}, \mathrm{y})}+\mathrm{USE}_{\mathrm{t}}=$ Demand $_{\mathrm{t}} \forall_{\mathrm{t}}$

Feasible Energy Dispatch: $\mathrm{GL}_{(\mathrm{g}, \mathrm{t})} \leq \operatorname{Pmax}\left(\right.$ Units $_{\mathrm{g}}+\sum_{\mathrm{y} \leq \mathrm{Y}}$ GBUnits $_{\mathrm{g}, \mathrm{y}}$ )

Feasible Builds: $\sum_{y \leq Y} G B_{g_{y}} \leq$ MaxGB Units $g_{g, y}$

$\sum_{y \leq Y} G B_{B J} \leq \mathrm{MaxGB}$ Units $B \nu$

PLEXOS models power flows using a linearized DC-OPF (Optimum Power flow), which refers to the generator dispatch and resulting $\mathrm{AC}$ power flows with respect to thermal limits on the AC transmission lines [11].

\section{B. System modelled}

The system incorporated in the analysis consists of the national interconnected grid and 38 non-interconnected islands ${ }^{2}$. Each island is represented through a node and each isolated electrical system through a region consisting of one or multiple nodes. The Greek National Grid System (NGS) comprises 6 representative nodes, as illustrated in

2 Assuming the state of the Greek electricity system in 2017, before interconnecting partially Syros, Paros and Mykonos electrical systems. However, the Cycladic Islands interconnection is included in the model and is realised in 2018 as it was scheduled. 
Fig. 1. Rhodes island system (region) comprises two nodes: Rhodes and the small island of Halki, interconnected and energy dependent on Rhodes.

\section{Modeling Input Assumptions}

Selected technoeconomic characteristics are presented in TABLE IV. and TABLE V. Heat rate was inserted in the model at three load points: $50 \%$ (if min stable level $<50 \%$ then min stable level), $75 \%$ and $100 \%$ of the total net capacity. The data describe points of the heat input function from which PLEXOS generates a piecewise linear model of the marginal heat rate function [11]. Fuel prices, carbon costs and inputs related to build costs are described in [12].

The forced outage rate (FOR) (5) for each of the conventional power generators is performed with the use of Monte Carlo simulation, based on statistics from 2015 and 2016. FOR was assumed to be $1.29 \% / y e a r / u n i t$, implying 113 hours out of service per year for each generator. The average maintenance factor is $1.2 \%$ /year/unit with a mean time to repair of 188 hours [4]. In this analysis, a uniform time distribution has been applied, where repair time varies in length homogeneously. The scheduled and unplanned outage factors for renewables are included in TABLE III.

$$
F O R=F O R h /(O h+F O R h)
$$

TABLE III. OUTAGE FACTORS FOR RES [13]-[15]

\begin{tabular}{|l|r|r|r|r|r|}
\hline $\begin{array}{l}\text { Techno- } \\
\text { logy }\end{array}$ & $\begin{array}{l}\text { FOR } \\
(\%)\end{array}$ & $\begin{array}{l}\text { Maintenance } \\
\text { Factor (\%) }\end{array}$ & $\begin{array}{l}\text { Mean } \\
\text { Time (h) }\end{array}$ & $\begin{array}{l}\text { Min } \\
\text { Time (h) }\end{array}$ & \multicolumn{1}{l|}{$\begin{array}{l}\text { Max } \\
\text { Time(h) }\end{array}$} \\
\hline Wind & $2 \%$ & $3 \%$ & 48 & 4 & 192 \\
\hline Solar & $1.5 \%$ & $2 \%$ & 16 & 3 & 120 \\
\hline $\begin{array}{l}\text { Solar } \\
\text { Thermal }\end{array}$ & $2.5 \%$ & $3 \%$ & 16 & 4 & 145 \\
\hline Hydro & $4.9 \%$ & $6.2 \%$ & 64 & 24 & 342 \\
\hline
\end{tabular}

TABLE IV. PERFORMANCE CHARACTERISTICS FOR POWER GENERATOR UNITS [4], [16]

\begin{tabular}{|c|c|c|c|c|c|c|}
\hline $\begin{array}{c}\text { Power } \\
\text { Generator }\end{array}$ & Type & $\mathrm{Nr}$ & $\begin{array}{c}\text { Max } \\
\text { Capacit } \\
\mathbf{y} \\
(\mathbf{M W})\end{array}$ & $\begin{array}{c}\text { HR } \\
(\mathbf{1 0 0 \%}) \\
(\mathbf{G J} / \mathbf{M} \\
\text { Wh })\end{array}$ & $\begin{array}{c}\text { Run up } \\
\text { rate } \\
\text { (MW/ } \\
\text { Min) }\end{array}$ & $\begin{array}{c}\text { Max } \\
\text { Rump } \\
\text { up } \\
\text { (MW/ } \\
\text { Min) }\end{array}$ \\
\hline $\begin{array}{c}20 \mathrm{x} \\
\text { MITSUBISHI } \\
\text { S16R }\end{array}$ & ICE & 2 & 25.5 & 12.30 & 1 & 2.4 \\
\hline $\begin{array}{c}\text { CEGIELSKI } \\
\text { B\&W 9RTA58 }\end{array}$ & ICE & 1 & 10.5 & 10.04 & 0.5 & 2 \\
\hline $\begin{array}{l}\text { ELECTRIM } \\
\text { JUGOTURBINA }\end{array}$ & ST & 2 & 14.5 & 15.82 & 0.1 & 2 \\
\hline $\begin{array}{c}\text { GE LM2500 } \\
\text { +HSPT }\end{array}$ & GT & 1 & 27 & 16.72 & 0.5 & 1.35 \\
\hline GE TM2500 & GT & 1 & 22 & 17.82 & 0.5 & 1.1 \\
\hline $\begin{array}{l}\text { PIELSTICK } \\
\text { 18VPC4.2-B }\end{array}$ & ICE & 3 & 18 & 11.51 & 1 & 2 \\
\hline $\begin{array}{c}\text { SIEMENS SGT } \\
600\end{array}$ & GT & 1 & 20 & 19.74 & 0.1 & 2 \\
\hline $\begin{array}{c}\text { THOMASSEN } \\
\text { PG5341 }\end{array}$ & GT & 1 & 17.5 & 27.06 & 0.1 & 2 \\
\hline
\end{tabular}

TABLE V. COST VARIABLES FOR POWER GENERATOR UNITS [4], [17]

\begin{tabular}{|c|c|c|c|c|}
\hline Type of Unit & $\begin{array}{c}\text { Start-up } \\
\text { cost } \\
(\boldsymbol{\epsilon} / \mathbf{M W})\end{array}$ & $\begin{array}{c}\text { Shut-down } \\
\text { cost } \\
(\boldsymbol{\epsilon} / \mathbf{M W})\end{array}$ & $\begin{array}{c}\text { VO\&M } \\
(\boldsymbol{\epsilon} / \mathbf{M W h})\end{array}$ & $\begin{array}{c}\text { FO\&M } \\
(\boldsymbol{\epsilon} / \mathbf{k W})\end{array}$ \\
\hline Diesel <20 MW & 12 & 10.8 & 1.2 & 45 \\
\hline Diesel $\geq 20 \mathrm{MW}$ & 8 & 6.7 & 0.9 & 45 \\
\hline Gas Turbines & 7 & 6.2 & 0.9 & 27.5 \\
\hline Steam Oil & 8 & 6.8 & 1 & 60 \\
\hline
\end{tabular}

In the context of this study, Rhodes interconnection will be realized between 2028 and 2030. Phase I (2028) proposes the interconnection of Rhodes with KosKalymnos power system via Telos and Nisyros islands. Following the immersion of the cable, Rhodes power station will supply power to the rest of the islands. Phase II (2030) proposes the interconnection of Dodecanese islands with Crete. The interconnection will operate with $\mathrm{AC}$ $2 * 280$ MVA cables. An upgrade of the proposed plan was considered in this analysis through the deployment of KosSamos interconnection $(2 * 280$ MVA), allowing for loads' transmission from the central and northern part of Greece.

Ancillary services provision approach is analytically described in [12]. Following Phase I, Kos-Kalymnos and Karpathos local thermal generation is gradually phased-out. Consequently, the capacities reserved in Rhodes will increase to meet the reserve requirements for the entire interconnected system. After the completion of Phase II, with the precondition to respect $\mathrm{N}-1$ criterion, local thermal generation on Rhodes island is gradually decommissioned.

Existing and planned $\mathrm{HV}$ and MV infrastructure was inserted in the model. TABLE VI. indicates the main characteristics and assumptions used for modelling submarine interconnections including the calculation of operating limits and losses as described in (6). The HV cables are imposed to a FOR of $5 \%$, and a maintenance rate per annum of $1.64 \%$ [18]. The time to repair is fluctuating between 168 and 1,448 hours with an average time at 840 hours [19], [20].

The hourly load profile of each system was input in the model for the reference year 2016. Five annual hourly wind and solar hourly profiles (2012-2016) [3], [21], [22] were inserted in the model as samples to reflect the wind and solar stochasticity for each node modelled. The ST plans ran for a single optimization incorporating five samples and yielding a single optimal set of capacity expansion decisions and one production solution.

$$
\text { Loss }=(\text { Resistance } / \text { MVA Base }) \times(\text { Flow })^{2}
$$

TABLE VI. INTERCONNECTIONS TECHNICAL CHARACTERISTICS [23]- [26]

\begin{tabular}{|l|l|l|l|}
\hline \multicolumn{1}{|c|}{$\begin{array}{c}\text { Interconnection } \\
\text { Project }\end{array}$} & \multicolumn{1}{|c|}{$\begin{array}{c}\text { Rhodes-Telos } \\
(\mathbf{x} 2)\end{array}$} & $\begin{array}{c}\text { Karpathos- } \\
\text { Rhodes (x2) }\end{array}$ & $\begin{array}{c}\text { Rhodes-Halki } \\
(\mathbf{x} 2)\end{array}$ \\
\hline Category & HV & HV & MV \\
\hline Year of Construction & 2027 & 2028 & 1989 \\
\hline Distance (km) & 25 & 85 & 14.7 \\
\hline Resistance (per unit) & 0.017 & 0.031 & 0.113 \\
\hline Reactance (per unit) & 0.019 & 0.190 & 0.001 \\
\hline Max Flow (MW) & 252 & 252 & 5.28 \\
\hline Build Cost (M€) & 44.9 & 43.4 & N/A \\
\hline FO\&M Cost (k€/year) & 359 & 347.2 & 150 \\
\hline
\end{tabular}

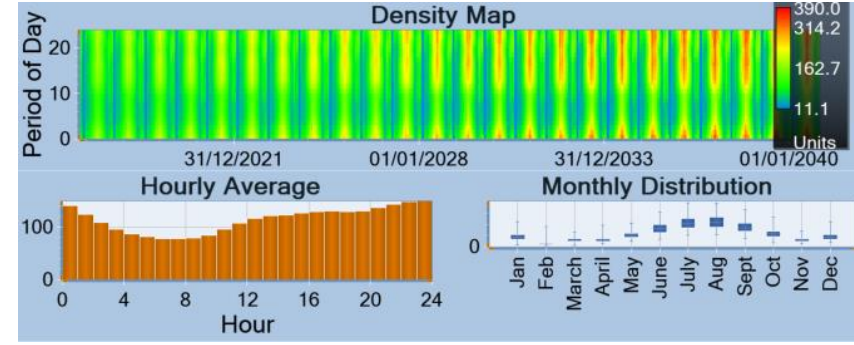

Fig. 2. Load Statistics (2020-2040) 


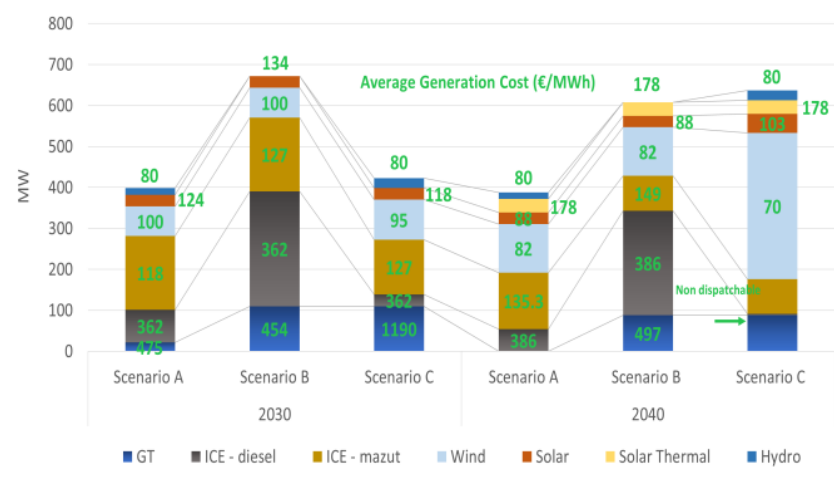

Fig. 3. Installed Capacity \& Average Generation Costs in 2030 \& 2040

\section{RESULTS}

The results emphasize two representative weeks: 1) week of $17-23$ November, recording statistically the annual minimum and 2) week 10 - 16 of August recording the annual maximum. These data derived from one year of hourly data (2016) combined with 5 years of monthly data (2012-2016). Fig. 2 illustrates statistics for the projection period (2020-2040). The distribution throughout the whole period shows that seasonal demand fluctuations are intense, attributed to high tourism volumes particularly during the summer months, resulting in rates of 15.6 visitors per one local citizen. Similarly, a daily pattern with hourly deviations intensified to $60 \%$ is observed.

\section{A. Scenario A-BAU, $2030 \& 2040$}

The BAU scenario demonstrates the continuation of the existing energy autonomy on the islands. Fig. 4 - Fig. 7 show that ICEs using mazut, present considerably lower generation costs and meet the baseload energy demand requirements. Diesel-fueled generators are dispatched to cover medium load and peak demand (especially in the MAX weeks as depicted in Fig. 4 and Fig. 6), while gas turbines with average costs exceeding $475 € / \mathrm{MWh}$ are used only as the 'ultimum refugium' for covering exceptional peaks and by 2040 they are phased out.

Renewable energy generators including solar, wind and hydro are dispatched with priority. By 2040, a 33 MW solar thermal generator with 6 hours thermal storage is introduced, shifting solar generation to cover the evening peaks between 17:00 and 22:00 when it is required. Wind capacity is increasing while solar and hydropower remain at the same levels. Curtailments occur in certain days when demand is at relatively low levels e.g. $13 \%$ curtailment on $21 / 11 / 2030$ and $55 \%$ on $17 / 11 / 2040$. Fig. 3, illustrates that BAU operation records the lowest capacity, causing marginal shortages, as the system is unable to meet demand levels exceeding $300 \mathrm{MW}$. Average generation costs follow the demand patterns particularly in the peak-load weeks. For the MIN load-demand the weekly average generation cost is decreasing as diesel-fired generation is constrained.

\section{B. Scenario B - Restrictions, $2030 \& 2040$}

Scenario B indicates that following 2030, despite the wind and solar penetration, thermal power generation restrictions to 500 hours per year will lead to severe outages, equal to $70-85 \%$ of the hourly demand, despite the considerable investments in new generation capacity. As expected, thermal generation limitations are reflected on higher local electricity costs (131-175 €/MWh for MIN and MAX weeks respectively) compared to Scenario A (128$158 € / \mathrm{MWh}$ ) in 2040 . In addition to this marginal increase, the constant unserved demand loads -not directly monetized- are charged with 3,000 €/MWh.

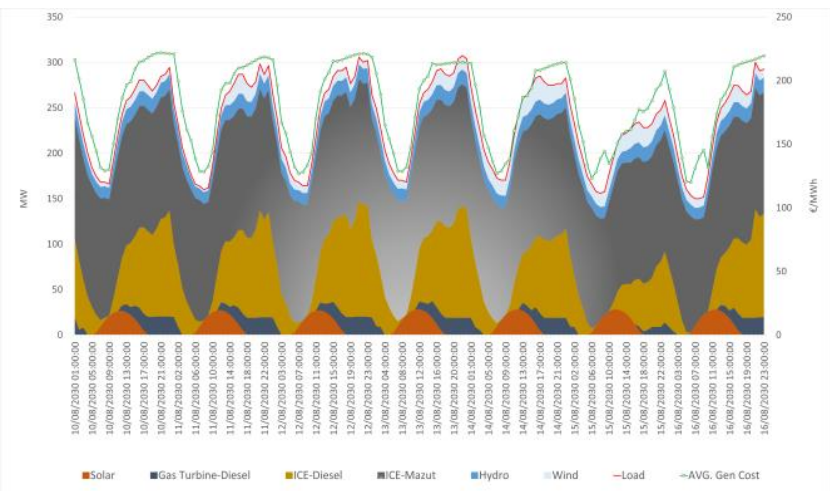

Fig. 4. Generation Mix - Rhodes, MAX (Scenario A)-2030

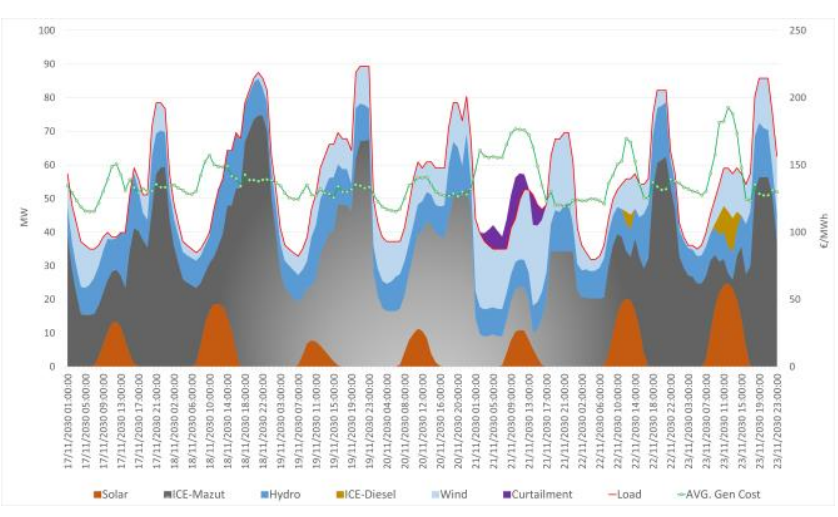

Fig. 5. Generation Mix - Rhodes, MIN (Scenario A)-2030

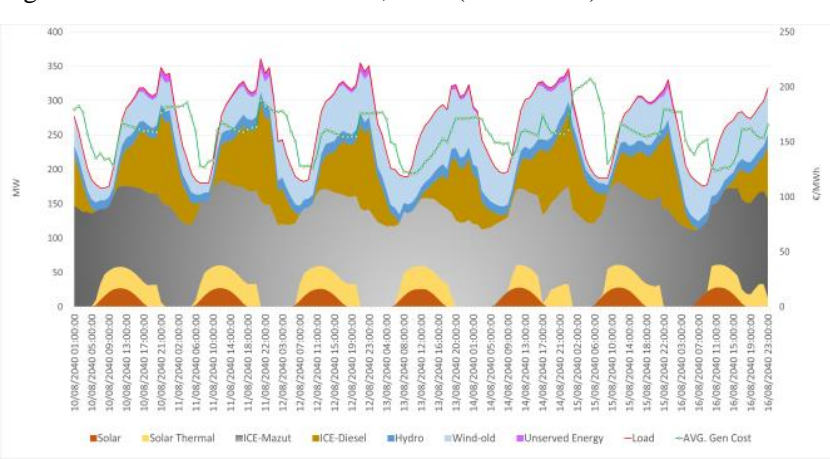

Fig. 6. Generation Mix - Rhodes, MAX (Scenario A)-2040

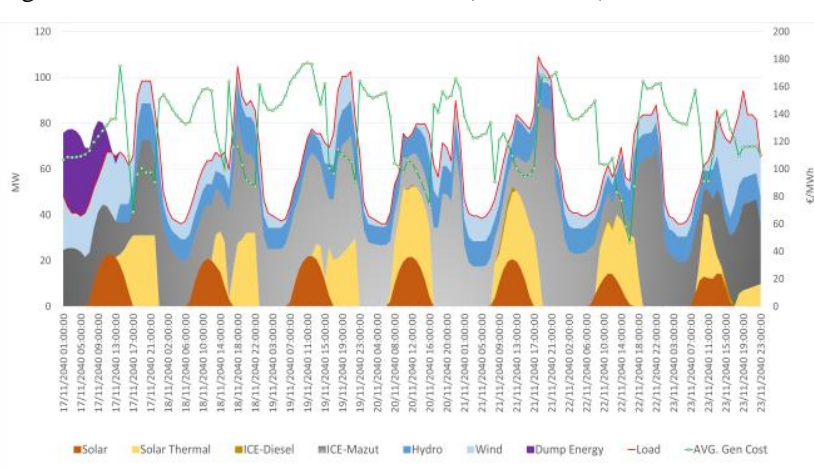

Fig. 7. Generation Mix - Rhodes, MIN (Scenario A)-2040 


\section{Scenario C-Interconnections, $2030 \& 2040$}

Presuming the interconnection is realized before 2030, Rhodes secures resilient power supply. RES development concerns mainly Rhodes island, on Halki photovoltaic capacity of $0.2 \mathrm{MW}$ is installed by 2030 . By 2040 wind accounts for the $78-82 \%$ of the generation. Fig. 8 to Fig. 11 show that generation from local thermal generators is significantly reduced by 2040 , while the majority has been retired, and those remaining, operate as tertiary reserves for the island. In 2040, during days of lower peak demand, Rhodes' electrical system transforms into a clean energy exporter, while wind curtailments and unserved loads are eliminated.

In 2030, local electricity generation costs are drastically reduced reflecting the RES levelized cost of energy ranging between 60 and $84 € / \mathrm{MWh}$. The average electricity cost on Rhodes is mirrored in the electricity costs recorded in the NGS with an average range between 95.3 $€ / \mathrm{MWh}$ and $125.3 € / \mathrm{MWh}$. By 2040 , the average electricity price on Rhodes is dropping to a range of 59.36-65 €/MWh as renewables are picking up at national level.

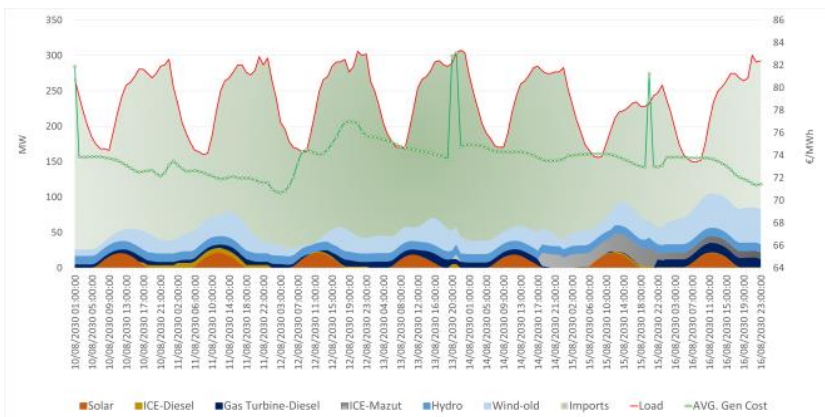

Fig. 8. Generation Mix - Rhodes, MAX (Scenario C) - 2030

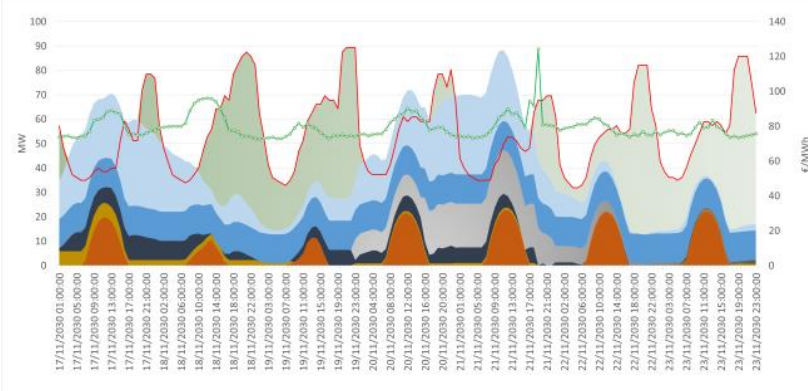

Fig. 9. Generation Mix - Rhodes, MIN (Scenario C) - 2030

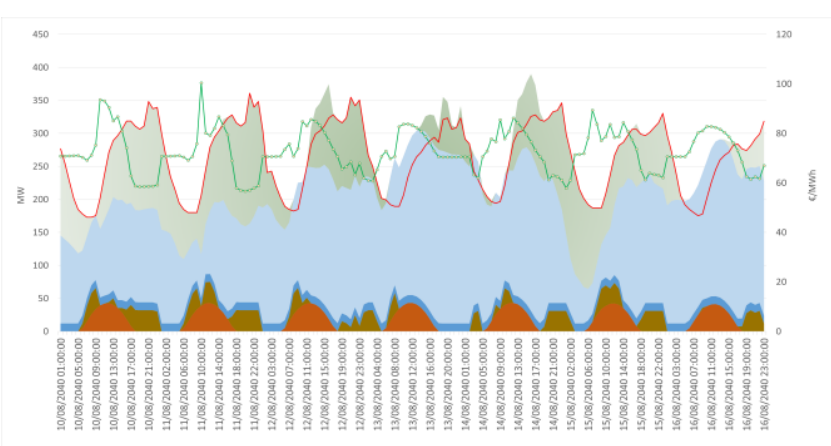

Fig. 10. Generation Mix - Rhodes, MAX (Scenario C) - 2040

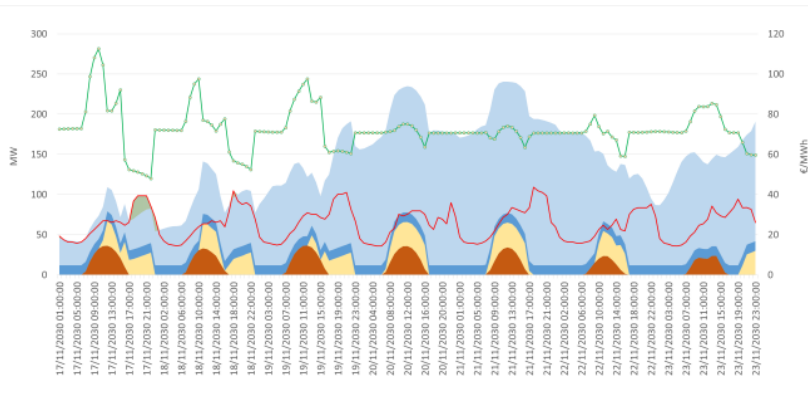

Fig. 11. Generation Mix - Rhodes, MIN (Scenario C) - 2040

\section{Electricity Interconnections Interchange}

Fig. 12 to Fig. 15 illustrate the electricity interchange (imports/exports) from and to Rhodes electrical system, including power flows of the three cables connected to Rhodes as mentioned in TABLE VI. It is evident that during the high demand season, the cables are mainly utilised to import electricity from the mainland while local wind energy is consumed insularly. On the contrary, within the winter months, the system exports energy to the main consumption centers in the mainland but for certain days in 2030 import dependence is still prevalent. By 2040, Rhodes-Telos interchange load is increasing denoting RES exports from Rhodes to the northern Dodecanese islands. Karpathos-Rhodes imports are decreasing as Rhodes has invested on local renewable energy development. The island of Halki as an energy dependent island with negligible local generation, imports power from Rhodes continuously.

Utilization rates, for the HV cables span between $4 \%$ and $53 \%$ for the MAX week in 2040. For the MIN week the range is narrowed down to $1 \%$ and $40 \%$, without creating any congestion phenomenon. A parametrical investigation exclusive of the additional cable of Kos-Samos shows that utilization rates reach $84 \%$ for the Karpathos Rhodes Interconnection, while the cable from Rhodes to Telos is used principally to import energy from Rhodes. Through this analysis underutilization of the cables' capacity is observed, however renewable energy acceleration following the time frame of this study could justify the selection of the 280 MVA cables, otherwise the redimensioning of the Dodecanese interconnection design would be recommended.

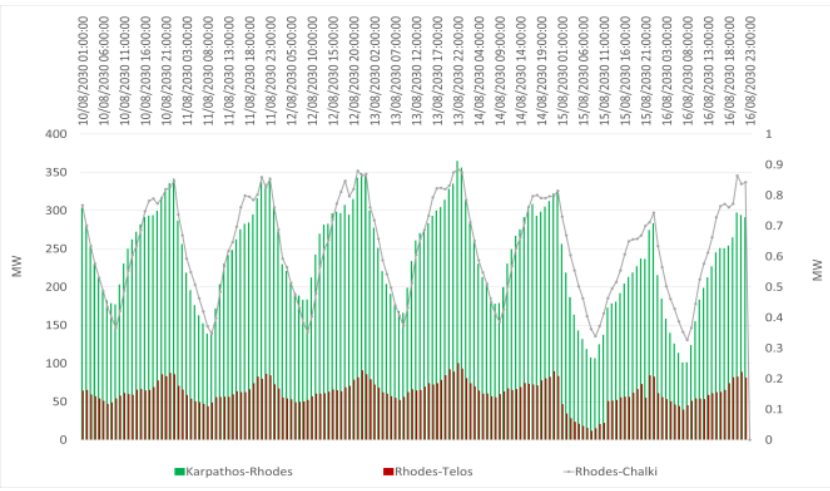

Fig. 12. Net Electricity Interchange, MAX - 2030 


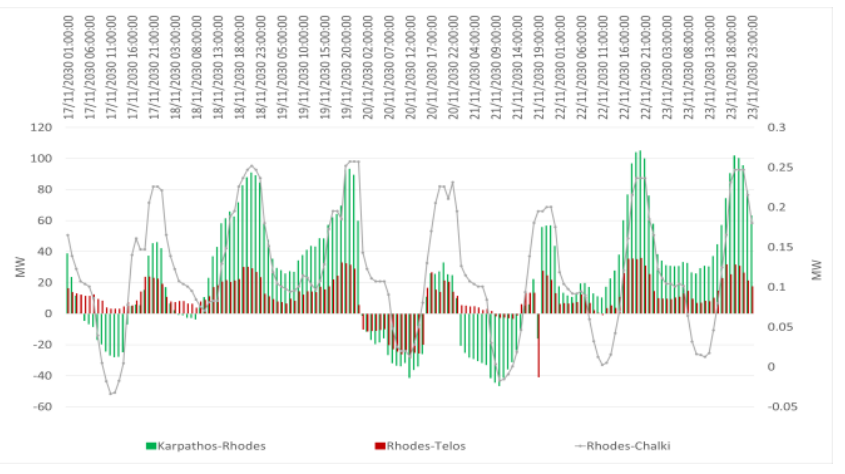

Fig. 13. Net Electricity Interchange, MIN - 2030

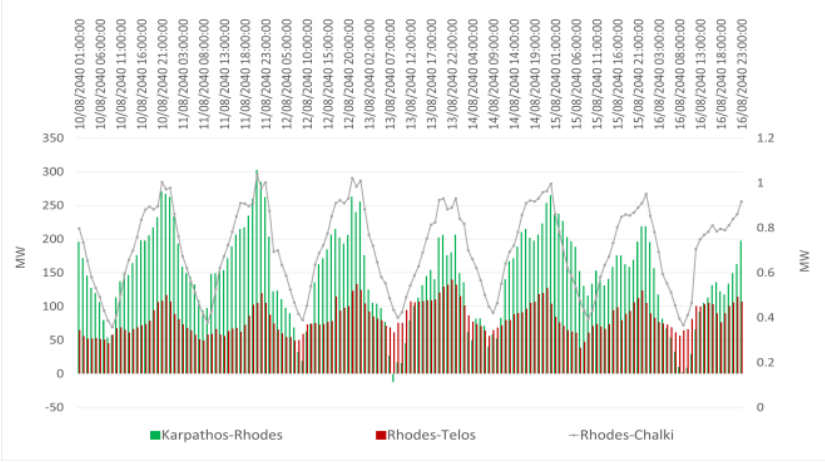

Fig. 14. Net Electricity Interchange, MAX - 2040

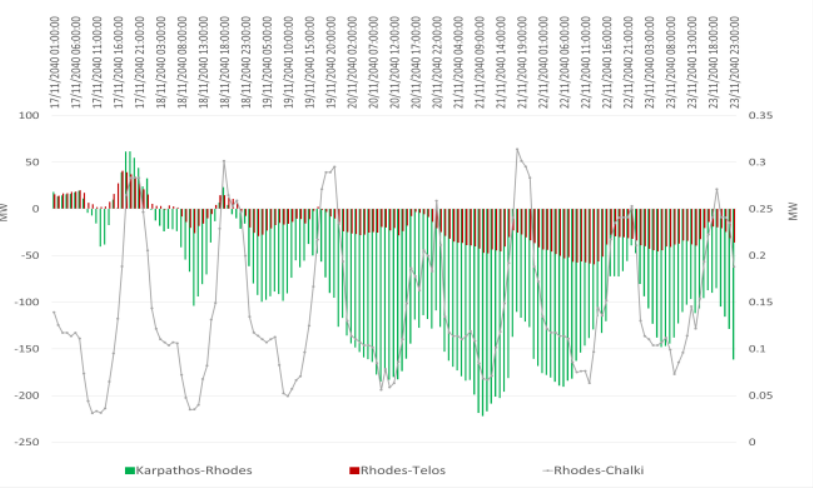

Fig. 15. Net Electricity Interchange, MIN - 2040

\section{CONCLUSIONS}

This paper analyses three future scenarios for the Greek non-interconnected electrical power system of RhodesHalki. The results focus on two representative weeks MIN and MAX for the milestone years of 2030 and 2040. They show that if energy isolation is to be continued on the island, electricity costs reach an average of $158.2 € / \mathrm{MWh}$ by 2040 (MAX week) and 131.98 €/MWh (MIN week). Costs reflect mainly future fuel prices, while the expected generation upgrade of the system is not adequate to meet annual peak demand load. Scenario B presents a nonfeasible solution for Rhodes as unserved energy loads are recorded throughout the examined weeks. The interconnection scenario determines power generation costs reduced by $58.9 \%$ for the MAX week $(59.36 € / \mathrm{MWh})$ and $54.8 \%$ ( $65 € / \mathrm{MWh})$ for the MIN week. Higher import loads are recorded in 2030 and respectively higher export loads in 2040 reaching $220 \mathrm{MWh}$, demonstrating the development of local renewable energy capacity replacing oil-fired regional generators and eventually electricity imports from the mainland.

\section{REFERENCES}

[1] European Commission, "Clean Energy for EU Islands," 2017. [Online]. Available: https://ec.europa.eu/energy/en/topics/energy-strategyand-energy-union/clean-energy-eu-islands. [Accessed: 01-Dec-2018]. [2] Hellenic Republic- Ministry of Environment Energy and Climate Change, "Approval of Public Service Obligation Costs for years 2014, 2015, 2016, FEK 688/2017," 2017.

[3] Hellenic Distribution Network Operator, "Statistics reports and monthly reports on Non-Interconnected Islands released," 2017. [Online]. Available: deddie.gr/en/themata-tou-diaxeiristi-mi-diasundedemenwnnisiwn/stoixeia-ekkathariseon-kai-minaion-deltion-mdn/miniaia-deltiaape-kai-thermikis-paragwgis-sta-mi/2017. [Accessed: 05-Aug-2017]. [4] Hellenic Electricity Distribution Network Operator, "Data for Autonomous Power Systems Power stations," 2017. [Online]. Available: https://www.deddie.gr/en. [Accessed: 15-Jun-2017].

[5] D. Al Katsaprakakis et al., "Introduction of a wind powered pumped storage system in the isolated insular power system of Karpathos-Kasos," Appl. Energy, vol. 97, pp. 38-48, 2012.

[6] Stefanos V. Papaefthymiou, Eleni G. Karamanou, Stavros A. Papathanassiou, and Michael P. Papadopoulos, "A Wind-Hydro-Pumped Storage Station Leading to High RES Penetration in the Autonomous Island System of Ikaria," Ieee Trans. Sustain. Energy, vol. 1, no. 3, pp. $163-172,2010$.

[7] A. V. Ntomaris, S. I. Vagropoulos, and A. G. Bakirtzis, "Integration of a hybrid power station in the insular power system of Crete," IEEE PES Innov. Smart Grid Technol. Conf. Eur., vol. 2015-Janua, no. January, pp. $1-6,2015$.

[8] C. Lignos and A. G. Tsikalakis, "Impact of Thera and Crete interconnection on their economic operation," IET, pp. 291-298, 2015.

[9] N. E. Koltsaklis, A. Dagoumas, G. Tsioni, and \#Christos Dikaiakos, "A mid-term, market-based power systems planning model," Appl. Energy, no. October, 2016.

[10] E. Zafeiratou and C. Spataru, "Sustainable island power system Scenario analysis for Crete under the energy trilemma index 2 , "Sustain. Cities Soc., vol. 41, no. January, pp. 378-391, 2018.

[11] Energy Exemplar, "PLEXOS WIKI." [Online]. Available: https://wiki.energyexemplar.com. [Accessed: 14-Oct-2017].

[12] E. Zafeiratou and C. Spataru, "Long Term analysis of submarine transmission grid extensions between the Greek islands and the mainland," in SEST 2019-2nd International Conference on Smart Energy Systems and Technologies, pp. 0-5.

[13] S. Pfaffel, S. Faulstich, and K. Rohrig, "Performance and Reliability of Wind Turbines : A Review," energies, no. Section 2, 2017.

[14] J. Ribrant, "Reliability performance and maintenance - A survey of failures in wind power systems," KTH, 2006.

[15] A. Myhr, C. Bjerkseter, A. Ågotnes, and T. A. Nygaard, "Levelised cost of energy for offshore fl oating wind turbines in a life cycle perspective," Renew. Energy, vol. 66, pp. 714-728, 2014.

[16] K. Van Den Bergh and E. Delarue, "Cycling of conventional power plants : technical limits and actual costs," no. March, 2015.

[17] N. Kumar, P. Besuner, S. Lefton, D. Agan, and D. Hilleman, "Power Plant Cycling Costs Power Plant Cycling Costs," no. April, 2012.

[18] D. Woodford, "Oahu Wind Integration and Transmission Study Hawaiian Islands Transmission Interconnection Project," February, 2011. [19] N. Hodge, "Power under the sea," pp. 26-29, 2005.

[20] H. Nugraha, Z. O. Silalahi, and N. I. Sinisuka, "The Use of Life Cycle Cost Analysis to Determine the Most Effective Cost of Power Interconnection System," vol. 3, no. 4, pp. 191-197, 2016.

[21] S. Pfenninger, A. Hawkes, and J. Keirstead, "Energy systems modeling for twenty-first century energy challenges," Renew. Sustain. Energy Rev., vol. 33, pp. 74-86, 2014.

[22] I. Staffell and S. Pfenninger, "Using bias-corrected reanalysis to simulate current and future wind power output," Energy, vol. 114, pp. 1224-1239, 2016.

[23] National Technical University of Athens, "Final Report 'Strategic Plan for the Interconnection of Non Interconnected Islands' to the Regulatory Authority for Energy of the Hellenic Republic," 2008. [24] NExans, "Submarine Power Cables," 2013.

[25]"XLPE Submarine Cable Systems Attachment to XLPE Land Cable Systems - User's Guide," 2010.

[26] Joint Research Center (JRC), "HVDC Submarine Power Cables in the World, Knowledge State-of-the-art," 2015. 